\title{
Determination Of Novel Antibacterial Triazolylmethyl Oxazolidinones Concentrations In Human Plasma By APCI-LC-MS: Application To Stability Study
}

\author{
Oludotun A. Phillips and Mohammed E. Abdel-Hamid \\ Department of Pharmaceutical Chemistry, Faculty of Pharmacy, Kuwait University, Kuwait.
}

Received, March 17, 2008; Accepted, May 12, 2008; Published, May 14, 2008.

\begin{abstract}
Triazolylmethyl oxazolidinones are novel potent antibacterial agents recently synthesized in our laboratory. PURPOSE. Development of a rapid and specific LC-MS method for evaluating the stability of three potentially active antibacterial triazolylmethyl oxazolidinone compounds, namely PH-27, PH-38 and PH-41, in human plasma. METHODS. Ion-trap mass spectrometry using +APCI-MS at $\mathrm{m} / \mathrm{z}$ 348.1 (PH-27), 389.1 (PH-38) and 451.1 (PH-41) combined with liquid chromatographic analysis using C18 reversed-phase column and a mobile phase consisting of $20 \mathrm{mM}$ ammonium acetate solution and acetonitrile (50:50 v/v) was used. Plasma samples were pre-treated with acetonitrile to precipitate proteins prior to LC-MS analysis. Linezolid was used as an internal standard whose predominant ion at $\mathrm{m} / \mathrm{z} 338.1$ was monitored and used to construct the calibration curves. An accelerated stability study under controlled experimental conditions was conducted at $-20{ }^{\circ} \mathrm{C}$ for a 5 -weeks period. RESULTS. Calibration curves of the examined oxazolidinones in human plasma were established (r: 0.99) up to the concentration of 20.0 $\mu \mathrm{g} \mathrm{ml}^{-1}$ with LLQ of 0.1 (PH-27), 0.5 (PH-38) and 1.0 $\mu \mathrm{g} \mathrm{ml}^{-1}$ (PH-41). Validation data showed appropriate intra- and inter-day precision and accuracy as indicated from RSD\% 1.3 - 8.6 and \% DEVs -12.7 to +11.3 , respectively. Stability studies gave the kinetic degradation parameters of $k_{\operatorname{deg}}$ 0.0191- 0.0857 week $^{-1}$, $\mathrm{t}_{1 / 2}$ 8.1-36.3 weeks and $\mathrm{t}_{90} 1.2$-5.5 weeks. CONCLUSIONS. The developed +APCI-LC-MS assay is simple, fast and specific method that could be applied for the routine analysis of the selected oxazolidinones during stability and pharmacokinetic studies. The examined compound $\mathrm{PH}-27$ was proved to be relatively more stable and resistant to degradation in human plasma compared to $\mathrm{PH}-38$ and $\mathrm{PH}-41$, as indicated from the kinetics and recovery studies at $-20{ }^{\circ} \mathrm{C}$.
\end{abstract}

\section{NOVELTY OF THE WORK}

Triazolylmethyl oxazolidinones are newly synthesized antibacterial agents with potent activity against Gram-positive cocci. The development of fast and specific analytical methods for measurement of oxazolidinone compounds in human plasma is important for stability and pharmacokinetic evaluations of compounds during biological studies. The developed LC-MS method, which employs a simple protein precipitation step was proven to be efficient in measuring oxazolidinone concentrations over a broad range covering the sub-therapeutic, therapeutic and toxic ranges.

\section{INTRODUCTION}

The emergence and wide spread development of resistant Gram-positive bacteria, namely methicillinresistant Staphylococcus aureus (MRSA), vancomycin-resistant Enterococcus faecium and Enterococcus faecalis; penicillin-resistant Streptococcus pneumoniae (PRSP) and multidrugresistant (MDR) coagulase-negative staphylococci (MR-CNS) continue to be major health concerns world-wide [1-4]. These occurrences, coupled with the recent isolations of vancomycin intermediateresistant (VISA), and vancomycin-resistant $S$. aureus (VRSA) with vancomycin minimum inhibitory concentration (MIC) $\geq 32 \mu \mathrm{g} / \mathrm{ml}$ [5-7] continue to serve as impetus for the development of new antibacterial agents. Oxazolidinones are novel class of antibacterial agents, with linezolid as the first and only member approved for the treatment of hospital-

Corresponding Author: Faculty of Pharmacy, Kuwait University, Kuwait; E-mail: dphillips@hsc.edu.kw 
and community-acquired pneumonia and skin infections caused by Gram-positive bacterial strains [1, 8-9]. Linezolid also showed activity against certain Gram-negative pathogens, particularly those associated with community-acquired respiratory tract infections (Moraxella catarrhalis and Haemophilus influenzae) and some anaerobes [9-10]. Oxazolidinones exhibit a unique mode of action by binding at the $P$ site of the 50 S ribosomal subunit thus inhibiting protein synthesis [11-12]. This unique mode of action offers a potential for low crossresistance with existing antimicrobial agents that inhibit protein synthesis. However, recent reports on emerging linezolid-resistant $S$. aureus [13] and Enterococcus spp. [14-16] in hospital isolates are discouraging and suggest the pressing need for new and more effective antibacterial agents.

We have recently reported [17] the bioisosteric substitution of the 5-azole moiety for the 5-acetamido group of linezolid 1 (Figure 1), which resulted in the novel 5-triazolylmethyl oxazolidinone PH-27, (Figure 1). This compound showed enhanced antibacterial activity against multi-drug resistant Gram-positive and certain anaerobes over linezolid [17-18]. Further structure-activity relationship studies from our laboratory showed that the introduction of different C4'-substituted acyl groups at the distal piperazine motif significantly enhanced the antibacterial activity against resistant pathogenic bacteria strains compared with linezolid and $\mathrm{PH}-27$ [19]. From these studies, two representative derivatives, namely acetylpiperazinyl (PH-38) and benzoylpiperazinyl (PH-41) derivatives (Figure 1) were selected based on their strong antibacterial activity both in the absence and presence of $50 \%$ human plasma for further study to determine their stability in plasma using LC-MS.

In addition, considerable interest on the novel triazolylmethyl oxazolidinone derivatives 2a-d as potential antibacterial agents for further development has been reported [20-22]. Also, the retention of antibacterial activity by $\mathrm{PH}-27, \mathrm{PH}-38$ and $\mathrm{PH}-41$ in the presence of plasma may be indicative of their relative stability in, and relatively low binding to human plasma proteins [19]. Liquid chromatography (LC) coupled with mass spectrometry (MS) is a well recognized powerful tool for analysis of drugs and their metabolites in biological samples with a high degree of selectivity and sensitivity. We have also reported on the application of LC-MS-MS in the determination of drug molecules including linezolid
[23], synercid [24], carbamazepine and theophylline [25] in biological and pharmaceutical matrices. Furthermore, other authors have utilized this technique to investigate the stability, metabolism and pharmacokinetics of selected oxazolidinone derivatives such as linezolid [26] and DA-7867 [2728]. In this study, we present the development, validation and application of positive atmospheric pressure-chemical ionization (+APCI)-LC-MS method for monitoring and comparing the stability of the novel triazolylmethyl oxazolidinones, namely $\mathrm{PH}-$ 27, PH-38 and PH-41 stored in human plasma at - 20 ${ }^{\circ} \mathrm{C}$ for a 5-weeks period.

\section{EXPERIMENTAL}

\section{Chemicals and reagents}

(R)-5-((1H-1,2,3-triazol-1-yl)methyl)-3-(3-fluoro-4morpholinophenyl) oxazolidin-2-one (Molecular weight: 347.35; PH-27), (R)-5-((1H-1,2,3-triazol-1yl)methyl) - 3 - ( 4 - (4-acetylpiperazin-1-yl) - 3 fluorophenyl)oxazolidin-2-one (Molecular weight: 388.40; PH-38) and (R)-5-((1H-1,2,3-triazol-1yl)methyl) - 3 - ( 4 - ( 4 - benzoylpiperazin - 1 - yl) - 3 -fluorophenyl) oxazolidin-2-one (Molecular weight: 450.48; PH-41), were synthesized in our laboratory according to literature methods [17,19]. (S)-N-((3-(3fluoro - 4 - morpholinophenyl) - 2 - oxooxazolidin - 5 -yl)methyl) acetamide (linezolid; Molecular weight: 337.35) was supplied as a gift from Pharmacia Inc. Human plasma samples were obtained from the Central Blood Bank, Kuwait. Water was purified using Milli-Q device (Millipore, Bedford, MA, USA). Other chemicals and reagents used were of analytical grade while solvents were of HPLC grade and used without further purification.

\section{Instruments}

Mass spectrometric analyses were performed using $\mathrm{LCQ}^{\mathrm{TM}}$ ion trap mass spectrometer (Finnigan, USA) fitted with APCI probe operated in positive mode. APCI was utilized with following parameters: discharge current $5.0 \mu \mathrm{A}$, vaporization temperature $450{ }^{\circ} \mathrm{C}$, capillary temperature $220{ }^{\circ} \mathrm{C}$, capillary voltage $7.0 \mathrm{~V}$, sheath gas flow rate $60 \mathrm{~L} / \mathrm{hr}$ and auxiliary gas flow $20 \mathrm{~L} / \mathrm{hr}$. The mass spectrometer was operated in full MS scanning mode over the range 150-500 amu. The mass scanning parameters were: molecular mass ions m/z 348.2 (PH-27), 389.2 
(PH-38), 451.2 (PH-41) and 338.2 (IS). The mass spectrometer was coupled to an HPLC (Spectra System P2000, Thermo Separation Products, USA) and an auto sampler (AS 3000, Finnigan Mat, USA). Chromatographic analyses were performed at ambient temperature $22{ }^{\circ} \mathrm{C}$ using a $\mathrm{C} 18$ reversed-phase column (Waters, 4.6 x $75 \mathrm{~mm}, 3.5 \mu \mathrm{m}$ diameter) and a mobile phase consisting of acetonitrile and $20 \mathrm{mM}$ ammonium acetate solution (50:50 v/v, pH 7.2) at a flow rate $1 \mathrm{ml} \mathrm{min}^{-1}$. All operation processes and data acquisition were controlled by the Xcalibur software.

\section{Standard solutions}

Stock solutions of PH-27, $\mathrm{PH}-38, \mathrm{PH}-41$ and linezolid as an internal standard (IS) were separately prepared by dissolving $\sim 5 \mathrm{mg}$ of each compound in 5 $\mathrm{ml}$ of acetonitrile to obtain a concentration of $1 \mu \mathrm{g} \mu \mathrm{l}^{-}$ ${ }^{1}$. Working solutions of the compounds were prepared in methanol/water $(50 / 50 \mathrm{v} / \mathrm{v})$ at two concentration ranges $0.1 \mu \mathrm{g} \mu \mathrm{l}^{-1}$ (low) and $0.5 \mu \mathrm{g} \mu \mathrm{l}^{-1}$ (high). A working solution of IS in acetonitrile was prepared at concentration of $0.002 \mu \mathrm{g} \mu \mathrm{l}^{-1}$. The stock and working solutions of oxazolidinones and IS were stored in refrigerator at $4{ }^{\circ} \mathrm{C}$ for a maximum of 2 weeks.

\section{Calibrators}

Aliquots of $1 \mathrm{ml}$ of human plasma samples spiked with the oxazolidinone solutions to give concentrations of $0.1,1.0,5.0,10.0$ and $20.0 \mu \mathrm{g} \mathrm{ml}^{-1}$ (PH-27), 0.5, 1.0, 5.0, 10.0 and $20 \mu \mathrm{g} \mathrm{ml}^{-1}$ (PH-38) and 1.0, 2.0, 5.0. 10.0 and $20.0 \mu \mathrm{g} \mathrm{ml}^{-1}$ (PH-41) were used to establish the calibration curves.

\section{Procedure for sample preparation for LC-MS analysis (protein precipitation)}

A $50 \mu \mathrm{l}$ aliquot of a plasma sample (calibrators, quality controls, and analytes) was mixed with $\sim 500$ $\mu \mathrm{l}$ of the internal standard solution in acetonitrile in $1.5 \mathrm{ml}$ - Eppendorff tube. The mixture was vortexed for $1 \mathrm{~min}$ and then centrifuged at $980 \mathrm{~g}$ at room temperature $22{ }^{\circ} \mathrm{C}$ for $10 \mathrm{~min}$. A $20 \mu \mathrm{l}$ aliquot of the clear supernatant was injected into LC-MS and analyzed under the previously determined LC-MS conditions.
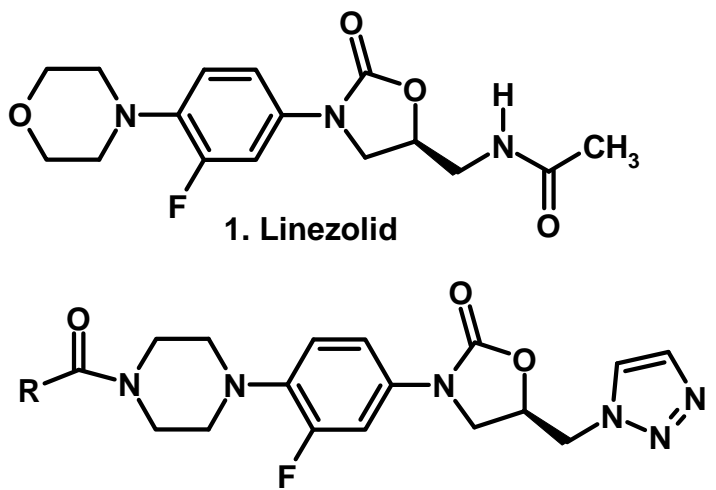

$\mathrm{PH}-38 ; \mathrm{R}=\mathrm{CH}_{3}$ $\mathrm{PH}-41 ; \mathrm{R}=\mathrm{Ph}$

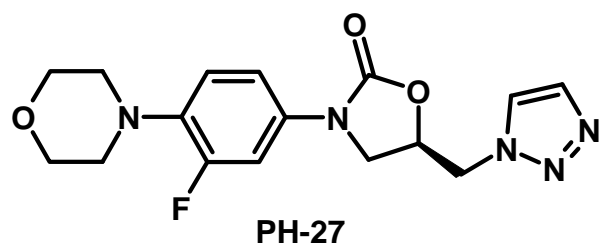

PH-27<smiles>[R][R]([R4]#C)=CN1C[C@H](Cn2cc([R])nn2)OC1=O</smiles>

2b: $\mathbf{R}=\mathrm{CH}_{3}$

2c: $\mathrm{R}=\mathrm{Br}$

2d: $\mathrm{R}=\mathrm{CH}_{2} \mathrm{CN}$

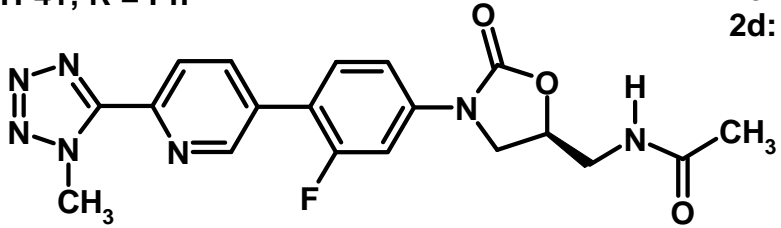

DA-7867

Figure. 1. Chemical structures of antibacterial oxazolidinones 


\section{Validation of LC-MS procedure for determination of triazolyl oxazolidinones}

\section{Linearity}

A $50 \mu \mathrm{l}$ aliquot of each calibrator in plasma was treated as described above. The calibration curve was constructed by plotting peak area ratio of Analyte / IS vs. concentration $\left(\mu \mathrm{g} \mathrm{ml} \mathrm{m}^{-1}\right)$. Linear regression equations representing the calibration curves were computed. For each analyte, the lower limit of quantitation (LLQ) was determined on the basis of the lowest concentration of oxazolidinone derivative that produces RSD\% and \%DEVs $<25 \%$.

\section{Precision and accuracy}

Quality control plasma samples supplemented with either $\mathrm{PH}-27$ or $\mathrm{PH}-38$ or $\mathrm{PH}-41$ at low $\left(3 \mu \mathrm{g} \mathrm{ml}^{-1}\right)$ and high $\left(15 \mu \mathrm{g} \mathrm{ml}^{-1}\right)$ concentrations were analyzed by the described LC-MS method. RSD\% and \%DEVs values were determined for each compound in one day to assess intra-day precision and accuracy. In addition, the inter-day precision and accuracy were also measured over a period of 3 weeks using plasma samples spiked with oxazolidinone at a concentration of $20 \mu \mathrm{g} \mathrm{ml}^{-1}$. The selectivity of APCI-LC-MS method was assessed by analysis of drug-free human plasma samples under the same experimental conditions.

\section{Recovery studies}

The described protein precipitation method was evaluated by determining the recovery percentages of $\mathrm{PH}-27, \mathrm{PH}-38$ and $\mathrm{PH}-41$, respectively from plasma samples spiked with known concentrations of oxazolidinones at concentrations of 3 and $15 \mu \mathrm{g} \mathrm{ml}^{-1}$.

\section{Stability studies}

Plasma samples (1 ml aliquots) were spiked with either $\mathrm{PH}-27$ or $\mathrm{PH}-38$ or $\mathrm{PH}-41$ at concentration 20 $\mu \mathrm{g} \mathrm{ml}{ }^{-1}$. The samples were stored at $-20{ }^{\circ} \mathrm{C}$ for 5 weeks. Aliquots were collected at weekly intervals, thawed to room temperature and treated as above. The remaining concentrations of the analytes ( $\mathrm{PH}-27, \mathrm{PH}-$ 38 and PH-41) expressed as log \% was plotted vs. time (weeks) to establish the stability profiles. The values of the degradation rate constant $\left(\mathrm{K}_{\mathrm{deg}}\right)$ were determined from the negative slopes of the stability curves, whereas $t_{1 / 2}$ and $t_{90}$ values were determined from the formulas $0.693 / \mathrm{k}_{\mathrm{deg}}$ and $0.105 / \mathrm{k}_{\mathrm{deg}}$, respectively. Furthermore, the residual concentrations of analytes from the frozen samples at $-20{ }^{\circ} \mathrm{C}$ were expressed as a percentage of the nominal concentrations added.

\section{RESULTS}

Figure 2a-b show representatives TIC chromatograms of $\mathrm{PH}-27$ and the internal standard linezolid with the full MS spectra of analytes at m/z 348.1 and 338.1, respectively. Similarly, PH-38 and PH-41 displayed the protonated molecular ions at $\mathrm{m} / \mathrm{z} 389.1$ and 451.1, respectively. These ions were used to generate the TIC chromatograms of compounds under the controlled LC-MS conditions. The tuning parameters for MS analysis by +APCI were optimized by direct infusion of each compound in the mobile phase into the APCI ionization probe. A vaporization temperature of $450{ }^{\circ} \mathrm{C}$, was found to be optimum to achieve maximum ionization and detection of mass ions by +APCI. Also the chromatographic conditions were also optimized. A mobile phase composed of acetonitrile and $20 \mathrm{mM}$ ammonium acetate solution in a ratio 1:1 was found to be the most appropriate for optimum detection of oxazolidinone derivatives and IS. A reversed-phase C18 column was appropriate as it permits good resolution of analytes from plasma. Protein precipitation using acetonitrile as a protein precipitant was appropriate to remove most of the interfering endogenous protein constituents before analysis. Under the selected LC-MS conditions, the examined triazolylmethyl oxazolidinones and IS were rapidly eluted at $1.09 \mathrm{~min}$ (PH-27), $0.88 \mathrm{~min}$ (PH-38), $1.24 \mathrm{~min}$ (PH-41) and $0.96 \mathrm{~min}$ (IS) as well-defined peaks.

The developed LC-MS method for quantitative measurement of oxazolidinones in plasma was evaluated and validated. Calibrators of oxazolidinone compounds in human plasma were prepared at five non-zero calibration standards over the ranges $0.1-20 \mu \mathrm{g} \mathrm{ml}^{-1}$ (PH-27), 0.5-20 $\mu \mathrm{g} \mathrm{ml}^{-1}$ (PH-38) and 1-20 $\mu \mathrm{g} \mathrm{ml}^{-1}$ (PH-41). Internal standard calibration using linezolid as IS was applied. Linear correlations (r: $\sim 0.99$ ) of the peak area ratio (Analyte / IS) and concentration ( $\left.\mu \mathrm{g} \mathrm{ml}^{-1}\right)$ were obtained with LLQ of $0.1,0.5$ and $1.0 \mu \mathrm{gml}^{-1}$ for PH-27, PH-38 and $\mathrm{PH}-41$, respectively. 


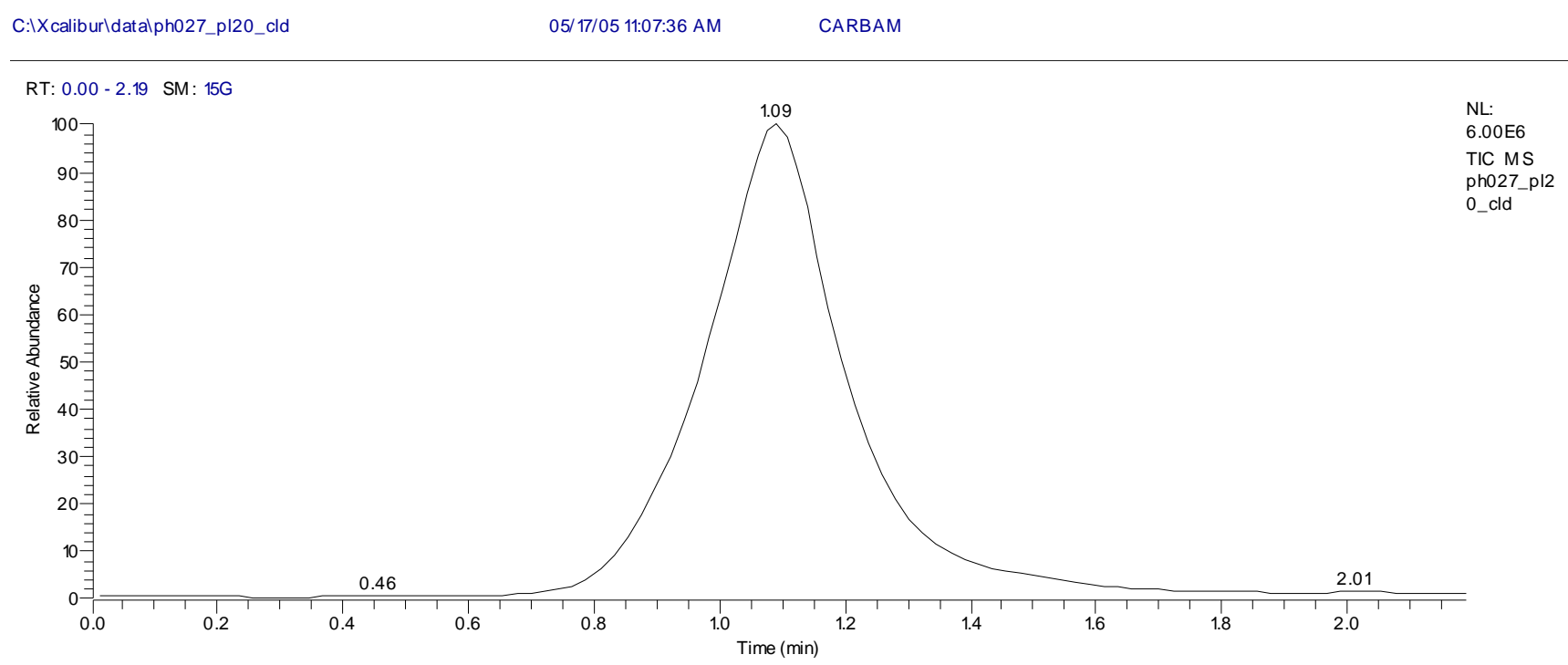

ph027_pl20_cld\#3 RT: 0.06 AV: 1 NL: 2.01E4

$\mathrm{T}:+\mathrm{c}$ Full ms2 348.20@10.00 [ 150.00-500.00]

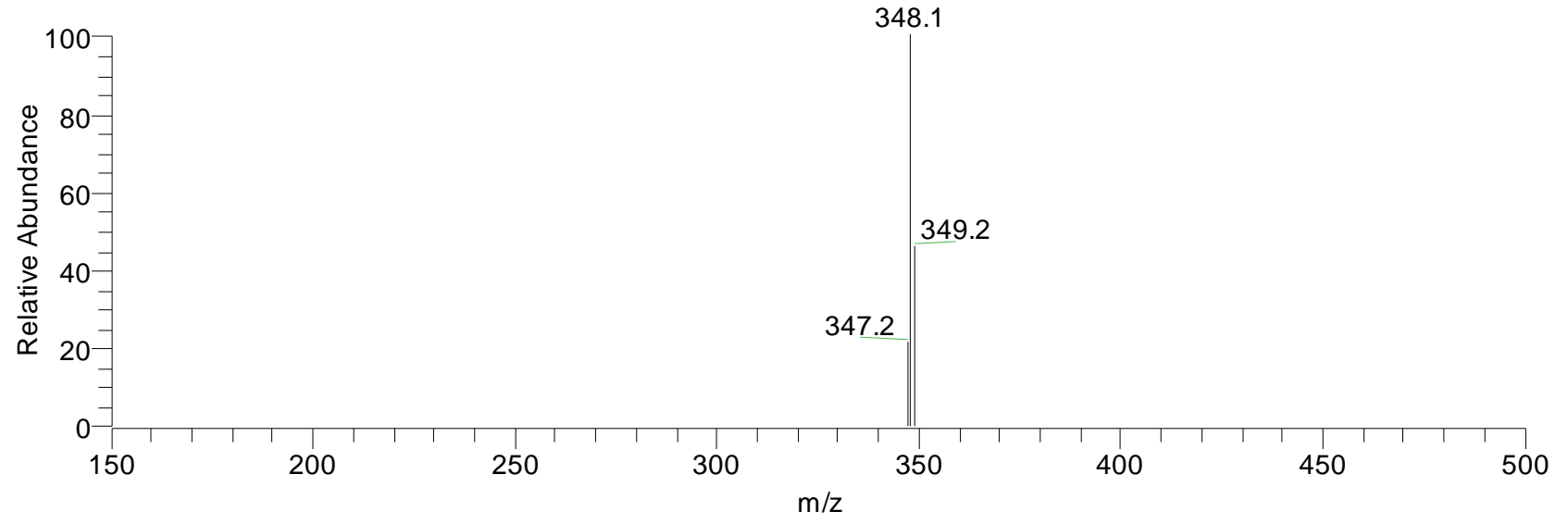

Figure. 2a. Representative TIC chromatogram of a human plasma spiked with PH-27 (Rt: 1.09 min) (C: $\left.5 \mu \mathrm{gml}^{-1}\right) \mathrm{using}^{+\mathrm{APCI}-}$ LC-MS (PH-27: m/z 348.1).

The RSD\% of the slopes of the calibration curves was in the ranges $(3.7-11.5 \%)$ (Table 1$)$. Intra-day precision and accuracy for QC plasma samples spiked with oxazolidinone compounds at $3 \mu \mathrm{gml}^{-1}$ (low) and $15 \mathrm{\mu gml}^{-1}$ (high) were in the ranges of (RSD\% : 1.3 8.6\% and (DEVs\%: -12.7 to +11.3 ), respectively (Table 2). Inter-day precision/accuracy study for QC plasma samples spiked with analytes at a concentration $20 \mathrm{\mu gml}^{-1}$ for a 3 -weeks period gave RSD\% values ranged from $3.7-7.8 \%$, whereas the inter-day \% DEVs ranged -12.1 to +5.1 for the examined oxazolidinones. To prove the efficiency of protein precipitation method for preparation of samples, recoveries of oxazolidinone compounds from human plasma were calculated. Mean recovery percentage \pm SD of $95.8 \pm 9.9$ (PH-27), $95.6 \pm 5.6$ (PH-38) and 106.1 \pm 4.1 (PH-41) in human plasma were computed.

The stability of oxazolidinones in plasma under storage conditions at $-20{ }^{\circ} \mathrm{C}$ for a 5 weeks period was evaluated. The derived stability results showed first-order kinetic profiles for the oxazolidinones with $K_{\mathrm{deg}}$ in the ranges of 0.0191 0.0857 week $^{-1}, \mathrm{t}_{1 / 2} 8.1$ - 36.3 weeks and $\mathrm{t}_{90}$ 1.2-5.5 weeks (Table 3). Moreover, the residual concentrations of oxazolidinones from the frozen samples at $-20^{\circ} \mathrm{C}$ after a 5 -weeks period were 91.6 , 71.1 and $62.3 \%$ for $\mathrm{PH}-27, \mathrm{PH}-38$ and $\mathrm{PH}-41$, respectively. 


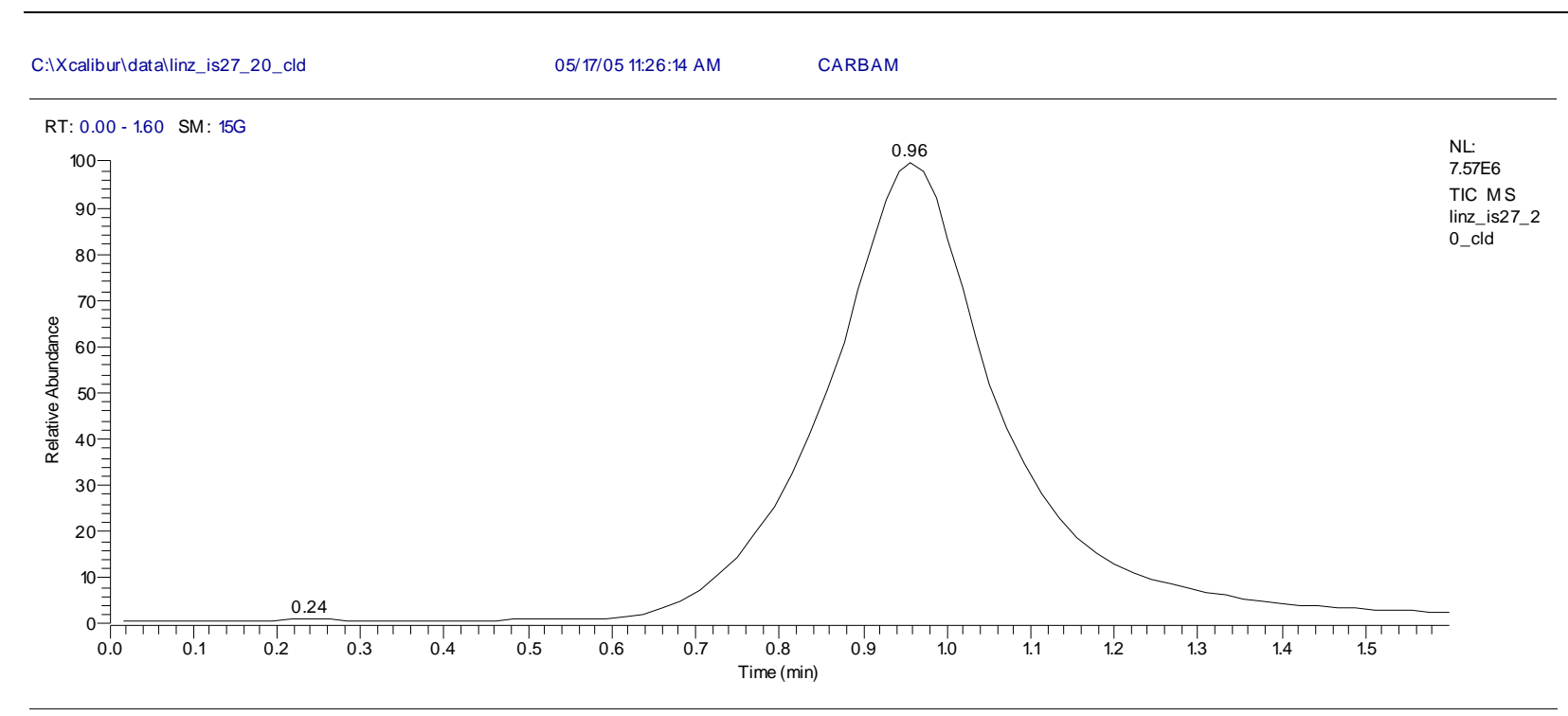

linz_is27_20_cld \#1 RT: 0.02 AV: 1 NL: 2.91E4

$\mathrm{T}:$ + c Full ms2338.20@10.00 [150.00-500.00]

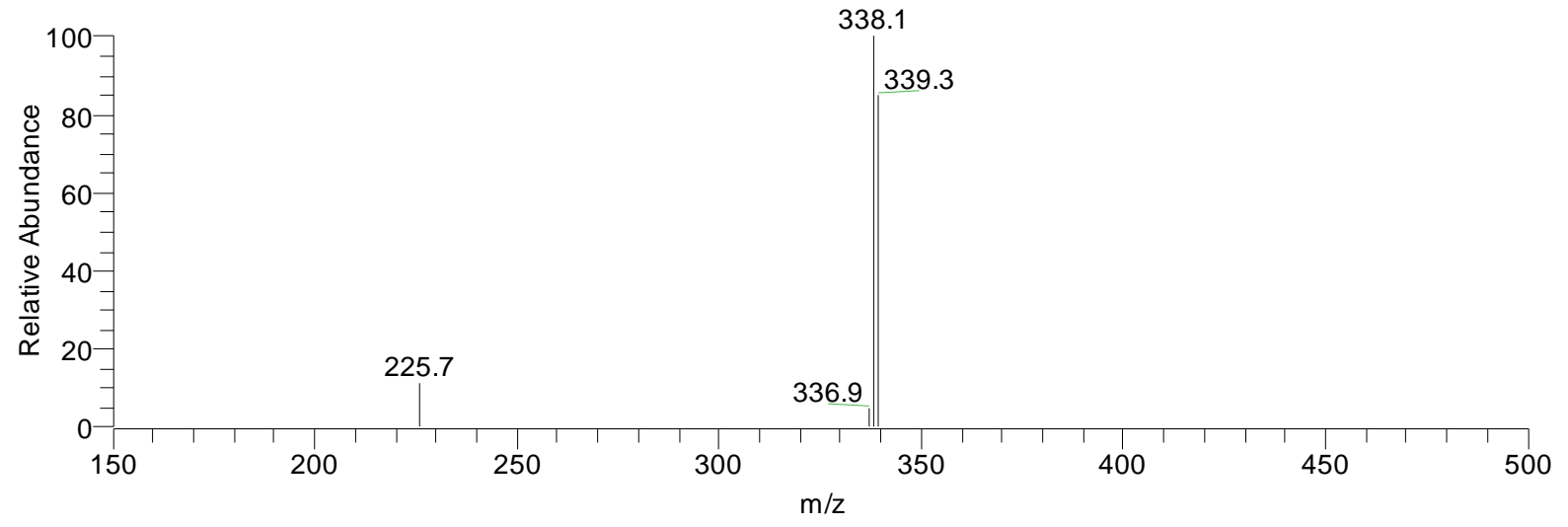

Figure. 2b.TIC chromatogram of a human plasma spiked with linezolid (Rt:0.96 min) as an internal standard (C: $\left.1 \mu \mathrm{gml}{ }^{-1}\right)$ using +APCI-LC-MS (linezolid: m/z 338.1).

Table 1. Summarized calibration data for the determination of triazolylmethyl oxazolidinones in human plasma by positive APCI-LC-MS. ${ }^{*} \mathrm{n}=10$

\begin{tabular}{rrrrrr} 
Compound & $\begin{array}{r}\text { Concentration } \\
\text { Range, } \mu g \cdot \mathrm{ml}^{-1}\end{array}$ & $\begin{array}{r}\text { Regression } \\
\text { equation }\end{array}$ & $\mathrm{R}^{2}$ & $\begin{array}{r}\text { LLQ } \\
\mu^{-1} . \mathrm{ml}^{-1}\end{array}$ & $\begin{array}{r}\text { RSD } \\
\text { of } \\
\text { slope }\end{array}$ \\
\hline PH-27 & $0.1-20$ & $0.05 \mathrm{x}+0.002$ & 0.9914 & 0.1 & 11.5 \\
PH-38 & $0.5-20$ & $0.02 \mathrm{x}+0.006$ & 0.9975 & 0.5 & 10.4 \\
PH-41 & $1.0-20$ & $0.01 \mathrm{x}+0.004$ & 0.9937 & 1.0 & 3.7 \\
\hline
\end{tabular}

\section{DISCUSSION}

Recently, the novel triazolylmethyl oxazolidinones, $\mathrm{PH}-27, \mathrm{PH}-38$ and $\mathrm{PH}-41$ have been prepared and tested in our laboratory as potential antibacterial agents. These compounds demonstrated potent antibacterial activity against both susceptible and multidrug-resistant Gram-positive bacterial strains
$[17,19]$. The stability of these compounds in human plasma is necessary to ensure the presence of effective and therapeutic drug levels. Ion-trap mass spectrometry (MS) was used in combination with LC for quantitative analysis of oxazolidinones in human plasma after simple cleaning up procedure using acetonitrile as a protein precipitant. During the early stage of method development, both ESI and APCI 
ionization interfaces coupled to MS were investigated for sensitivity. Significant gain in sensitivity by the use of APCI at $450{ }^{\circ} \mathrm{C}$ was observed, while ESI was found to produce insufficient ionization. This indicated that the APCI performed better for high molecular weight and slightly polar triazolylmethyl oxazolidinones. In addition, the composition of the mobile phase was also found to be important. The presence of acetonitrile as a modifier in the mobile phase at $50 \% \mathrm{v} / \mathrm{v}$ permits rapid and enhanced detection of analytes within $\sim 2 \mathrm{~min}$. Unlike classical LC with UV detection, chromatographic analysis using LC-MS, which is based on the detection of analytes by monitoring the molecular mass ions, is more selective compared to the traditional LC with UV detection. Accordingly, the potential interference from endogenous biological constituents of the plasma using HPLC was eliminated during analysis of oxazolidinones using LC-MS with an improvement of method selectivity. As shown in Figure 3, the ion chromatograms of free plasma samples similarly treated as spiked samples, showed zero peak area measurements in the range $0-2 \mathrm{~min}$ at the retention times of oxazolidinones and IS. Further, the supplemented plasma samples with analytes gave recovery percentages of $\sim 100 \pm 6 \%$ of oxazolidinones, indicating insignificant ion suppressing effect of plasma and proved an appropriate selectivity for the developed LC-MS method. This resulted in far cleaner and less contaminated chromatographic profiles for the oxazolidinones. The developed LC-MS method covers a broad range of the oxazolidinone compounds in plasma at the concentration range of $\sim 0.1-20 \mu \mathrm{g}$ $\mathrm{ml}^{-1}$, and simulates sub-therapeutic, therapeutic and toxic levels, which are important for pre-clinical and clinical studies. In addition to linearity, sensitivity and selectivity studies; intra-day and inter-day precision and accuracy studies at low, medium and high concentrations of oxazolidinones in plasma were conducted. As indicated in Table 2, the developed LC-MS method was found to be appropriate for measuring $\mathrm{PH}-27, \mathrm{PH}-38$ and $\mathrm{PH}-41$ in plasma. The relatively low inter-day precision and accuracy values for PH-38 and PH-41 (Table 2) may be due to the relative instability of these compounds in human plasma. The calculated recovery percentages as previously shown indicated that the protein precipitation method is appropriate for sample preparation. Moreover, the applied procedure is fast, simple, non-tedious and may be appropriate for the analysis of a large sample size during biological studies.

The conducted stability studies revealed that PH-27, PH-38 and PH-41 compounds have different stability profiles in human plasma when stored at -20 ${ }^{\circ} \mathrm{C}$; however the stability was found to be somewhat related to the chemical structure of the oxazolidinone compounds. Whereby, the morpholino derivative (PH-27) was found to be the most stable compound compared with the acylpiperazinyl derivatives ( $\mathrm{PH}-38$ and $\mathrm{PH}-41$ ) as indicated from lower $\mathrm{K}_{\mathrm{deg}}$, longer $\mathrm{t}_{1 / 2}$ and $t_{90}$ and higher percentages of the residual oxazolidinones at $-20{ }^{\circ} \mathrm{C}$; $\mathrm{PH}-27$ (91.6\%), $\mathrm{PH}-38$ (71.1\%) and $\mathrm{PH}-41$ (62.3\%). These differences in stability behaviors might be due to the presence of the acyl moiety at the distal piperazine 4-position, which could be susceptible to hydrolysis by plasma amidases.

Table 2. Intra- and inter-day precision and accuracy for the determination of triazolylmethyl oxazolidinones in human plasma by positive APCI-LC-MS following protein precipitation. ${ }^{*} n=8 \quad{ }^{*} n=4$

\begin{tabular}{|c|c|c|c|c|c|}
\hline Compound & Nominal & $\begin{array}{r}\text { Concentration } \\
\mu \mathrm{g} . \mathrm{ml}^{-1} \\
\end{array}$ & Found (mean \pm SD) $\mu \mathrm{g} \cdot \mathrm{ml}_{1}^{-}$ & $\begin{array}{c}\text { RSD\%* }^{*} \\
\text { Precision } \\
\end{array}$ & $\begin{array}{l}\text { \%DEVs* } \\
\text { Accuracy }\end{array}$ \\
\hline \multirow{3}{*}{ PH-27* } & & & Intra-day & & \\
\hline & & 3.0 & $2.9 \pm 0.2$ & 6.9 & -6.7 to +3.3 \\
\hline & & 15 & $13.9 \pm 1.2$ & 8.6 & -12.7 to +1.3 \\
\hline \multirow{2}{*}{ PH-38* } & & 3.0 & $2.9 \pm 0.1$ & 3.4 & -10.7 to +2.3 \\
\hline & & 15 & $14.3 \pm 0.9$ & 6.3 & -12.2 to +6.9 \\
\hline \multirow[t]{3}{*}{ PH-41* } & & 3.0 & $3.1 \pm 0.1$ & 3.2 & +0.7 to +11.3 \\
\hline & & 15 & $15.4 \pm 0.2$ & 1.3 & +1.7 to +4.1 \\
\hline & & & Inter-day & & \\
\hline PH-27** & & 20 & $19.1 \pm 0.7$ & 3.7 & -8.5 to +5.1 \\
\hline PH-38** & & 20 & $19.3 \pm 1.5$ & 7.8 & -12.1 to +2.5 \\
\hline PH-41** & & 20 & $18.9 \pm 1.3$ & 6.9 & -11.2 to +1.5 \\
\hline
\end{tabular}




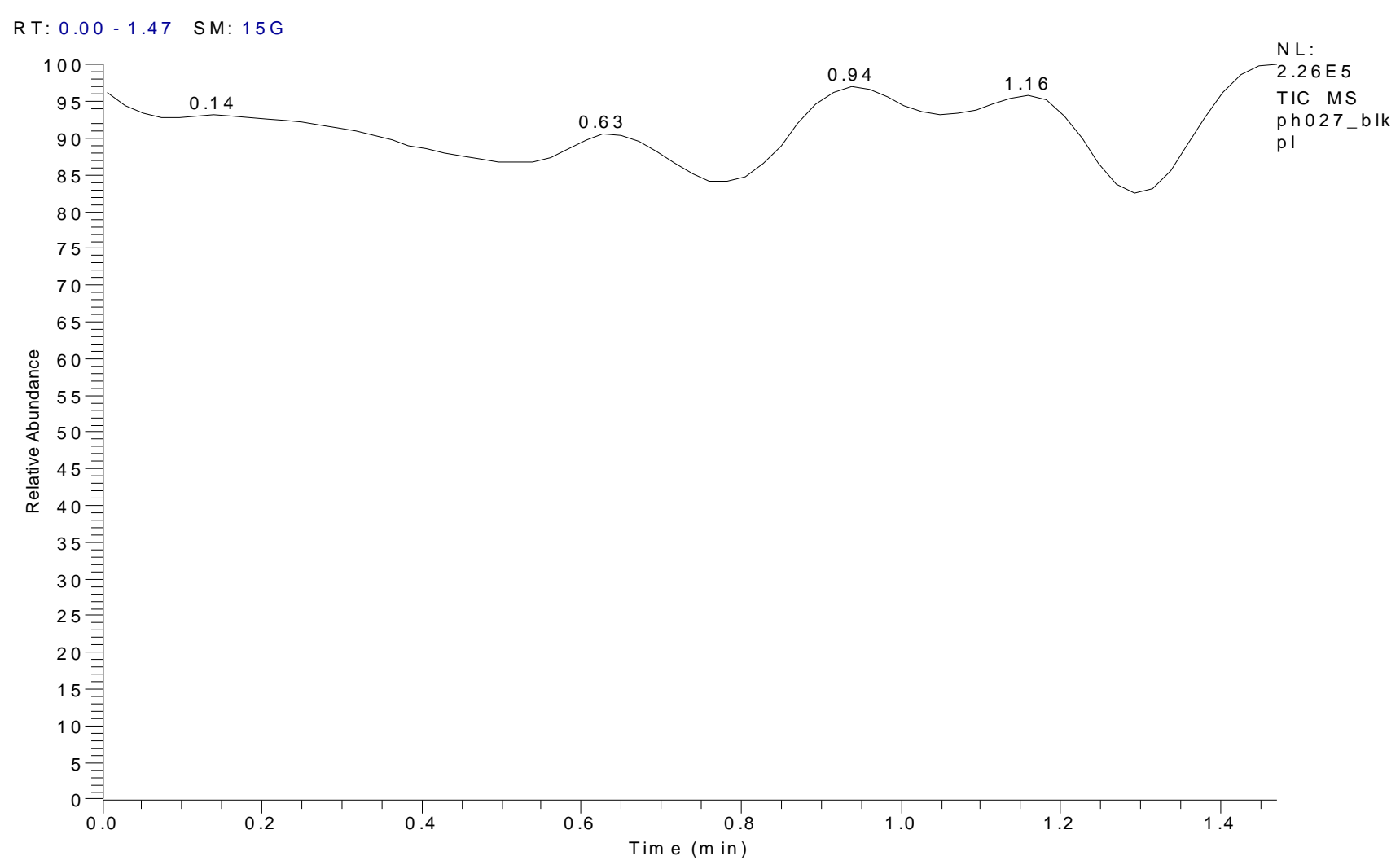

Figure 3. TIC chromatogram of a 50- $\mu$ l aliquot of free human plasma (Blank) after treatment with acetonitrile, using +APCILC-MS.

Table 3. Kinetic parameters of the stability study of triazolylmethyl oxazolidinones in human plasma at $-20{ }^{\circ} \mathrm{C}$ determined by positive APCI-LC-MS

\begin{tabular}{rrrr} 
Compound & $\mathrm{K}_{\text {deg }}\left(\right.$ week $\left.^{-1}\right)$ & $\mathrm{t}_{1 / 2}$ (week) & $\mathrm{t}_{90}$ (week) \\
\hline PH-27 & 0.0191 & 36.3 & 5.5 \\
PH-38 & 0.0716 & 9.7 & 1.5 \\
PH-41 & 0.0857 & 8.1 & 1.2 \\
\hline
\end{tabular}

\section{CONCLUSIONS}

The described APCI-LC-MS method provides the advantages of selectivity and sensitivity for analysis of triazolylmethyl oxazolidinones in complex matrices with rapid chromatographic elution of analytes. Validation and recovery studies using protein precipitation method supported the potential applicability of this method for analyzing oxazolidinone compounds in human plasma and for evaluating the stability of compounds in biological matrixes. The conducted studies have showed that the prepared triazolylmethyl oxazolidinones have different stability profiles when stored at $-20{ }^{\circ} \mathrm{C}$ for a 5-weeks period. $\mathrm{PH}-27$ was the most stable compound as indicated by the lower $K_{\text {deg, longer }} t_{1 / 2}$ and $t_{90}$ values and higher percentage of the residual amount from the stored samples at $-20^{\circ} \mathrm{C}$, compared with $\mathrm{PH}$ 38 and $\mathrm{PH}-41$.

\section{ACKNOWLEDGEMENTS}

This work was supported by Research Administration, Kuwait University Grant Numbers PC01/05 (OAP); GS01/01 and GS03/01 (Science Analytical Facilities, SAF). 


\section{REFERENCES}

[1]. Wookey A, Turner PJ, Greenhalgh JM, Eastwood M, Clarke J, Sefton C. AZD2563, a novel oxazolidinone: definition of antibacterial spectrum, assessment of bactericidal potential and the impact of miscellaneous factors on activity in vitro. Clin. Microbiol. Infect. 10:247-254, 2004.

[2]. Wisplinghoff H, Bischoff T, Tallent SM, Seifert H, Wenzel RP, Edmond MB. Nosocomial bloodstream infections in US hospitals: analysis of 24,179 cases from a prospective nationwide surveillance study. Clin. Infect. Dis. 39(3):309-17, 2004.

[3]. Lowy FD. Staphylococcus aureus infections. N. Engl. J. Med. 339:520-532, 1998.

[4]. Fauci AS, Touchette NA, Folkers GK. Emerging infectious diseases: a 10-year perspective from the National Institute of Allergy and Infectious Diseases. Emerg. Infect. Dis. 11(4):519-25, 2005.

[5]. Centers for Disease Control and Prevention. Staphylococcus aureus resistant to vancomycin-United States, 2002. Morb. Mort. Rep. 51(26):565567, 2002.

[6]. Centers for Disease Control and Prevention. Vancomycin-resistant Staphylococcus aureus-Pennsylvania, 2002. Morb. Mort. Rep. 51(40):902903, 2002.

[7]. Centers for Disease Control and Prevention. Vancomycin-resistant Staphylococcus aureus - New York, 2004. Morb. Mort. Rep. 53(15):322-323, 2004.

[8]. Wilcox MH. Update on linezolid: the first oxazolidinone antibiotic. Expert. Opin. Pharmacother. 6(13):2315-2326, 2005.

[9]. Moellering RC. Linezolid: the first oxazolidinone antimicrobial. Ann. Intern. Med. 138(2):135-142, 2003.

[10]. Hutchinson DK. Oxazolidinone antibacterial agents: a critical review. Curr. Top. Med. Chem. 3(9):10211042, 2003.

[11]. Bozdogan B, Appelbaum PC. Oxazolidinones: activity, mode of action, and mechanism of resistance. Int. J. Antimicrob. Agents 23(2):113119, 2004.

[12]. Sinclair A, Arnold C, Woodford N. Rapid detection and estimation by pyrosequencing of 23S rRNA genes with a single nucleotide polymorphism conferring linezolid resistance in Enterococci. Antimicrob. Agents Chemother. 47(11):3620-3622, 2003.

[13]. Tsiodras S, Gold HS, Sakoulas G, Eliopoulos GM, Wennersten C, Venkataraman L, Moellering RB Jr., Ferraro MJ. Linezolid resistance in a clinical isolate of Staphylococcus aureus. Lancet 358(9277):207208, 2001.
[14]. Gonzales RD, Schreckenberger FC, Graham MB, Kelkar S, DenBesten K, Quinn JP. Infections due to vancomycin-resistant Enterococcus faecium resistant to linezolid. Lancet 357(9263):1179, 2001.

[15]. Johnson AP, Tysall L, Stockdale MW, Woodford N, Kaufmann ME, Warner M, Livermore DM, Asboth F, Allerberger FJ. Emerging linezolidresistant Enterococcus faecalis and Enterococcus faecium isolated from two Austrian patients in the same intensive care unit. Eur. J. Clin. Microbiol. Infect. Dis. 21(10):751-754, 2002.

[16]. Rahim S, Pillai K, Gold HS, Venkataraman L, Inglma K, Press RA. Linezolid-resistant, vancomycin-resistant Enterococcus faecium infection in patients without prior exposure to linezolid. Clin. Infect. Dis. 36(11):E146-148, 2003.

[17]. Phillips OA, Udo EE, Ali AAM, Al-Hassawi N. Synthesis and antibacterial activity of 5-substituted oxazolidinones. Bioorg. Med. Chem. 11(1):35-41, 2003.

[18]. Phillips OA, Rotimi VO, Jamal WJ, Shahin M, Verghese TL. Comparative in vitro activity of PH027 versus linezolid and other anti-anaerobic antimicrobials against clinical isolates of Clostridium difficile and other anaerobic bacteria. J. Chemother. 15(2):113-117, 2003.

[19]. Phillips OA, Udo EE, Ali AAM, Samuel SM. Synthesis and antibacterial activity of new $\mathrm{N}$-linked 5-triazolylmethyl oxazolidinones. Bioorg. Med. Chem. 13(12):4113-4123, 2005.

[20]. Reck F, Zhou F, Girardot M, Kern G, Eyermann CJ, Hales NJ, Ramsay RR, Gravestock MB. Identification of 4-substituted 1,2,3-triazoles as novel oxazolidinone antibacterial agents with reduced activity against monoamine oxidase A. J. Med. Chem. 48(2):499-506, 2005.

[21]. Gravestock MB. Recent developments in the discovery of novel oxazolidinone antibacterials. Curr. Opin. Drug. Discov. Develop. 8(4):469-477, 2005.

[22]. Renslo AR, Luehr GW, Gordeev MF. Recent developments in the identification of novel oxazolidinone antibacterial agents. Bioorg. Med. Chem. 14(12):4227-4240, 2006.

[23]. Phillips OA, Abdel-Hamid ME, Al-Hassawi N. Determination of linezolid in human plasma by LCMS-MS. Analyst 126(5):609-614, 2001.

[24]. Abdel-Hamid ME, Phillips OA. LC-MS/MS determination of Synercid ${ }^{\circledR}$ injections. J. Pharm. Biomed. Anal. 32:1167-1174, 2003.

[25]. Abdel-Hamid ME, Phillips OA. LC-MS/MS determination of carbamazepine, pindolol and theophylline in human serum. J. Liq. Chromatogr. Related Technolog. 26(12):1937-1957, 2003.

[26]. Slatter JG, Stalker DJ, Feenstra KL, Welshman IR, Bruss JB, Sama JP, Johnson MG, Sanders PE, 
Hauer MJ, Fagerness PE, Stryd RP, Peng GW, Shobe EM. Pharmacokinetics, metabolism, and excretion of linezolid following an oral dose of [(14)C]linezolid to healthy human subjects. Drug Metab. Dispos. 29(8):1136-1145, 2001.

[27]. Bae SK, Chung W-S, Kim EJ, Rhee JK, Kwon JW, Kim WB, Lee MG. Pharmacokinetics, blood partition and protein binding of DA-7867, a new oxazolidinone. Biopharm. Drug Dispos. 25(3):127135, 2004.

[28]. Ji HY, Lee HW, Chang SG, Lee JJ, Rhee JK, Kim WB, Lee HS. Liquid chromatography-tandem mass spectrometry for the determination of a new oxazolidinone antibiotic DA-7867 in human plasma. Biomed. Chramatogr. 18(2):86-89, 2004. 